\title{
Soil Vapor Extraction Removal of Semi Volatile Organic Compounds in Soil: A Pilot-scale Study
}

\author{
Chi Zhang ${ }^{1}$, Xiao Chen ${ }^{2}$, Yingyu Tan ${ }^{1}$, Yijian Feng ${ }^{1}$ and Zhong Zhong ${ }^{1, *}$ \\ ${ }^{1}$ Zhejiang Environmental Science \& Design Institute, Hangzhou, Zhejiang, 310007, China \\ ${ }^{2}$ Taizhou Environmental Protection Bureau, Taizhou, Zhejiang, 318001, China \\ ${ }^{*}$ Corresponding author
}

\begin{abstract}
Semi Volatile Organic Compounds (SVOCs) contamination in soil was a widespread problem in China due to industrial pollutants leak and discharge. A pilot study of SVE and related combination techniques was demonstrated for soil contaminated with SVOCs. A miniaturization SVE system was applied in research and performance of this extraction system was measurement. The results of the field test showed that single SVE treatment has limited effect in SVOCs removal and combination of chemical oxidation with SVE and heating SVE could get a better remediation effect of $89 \%$ removal and costs $216 \mathrm{RMB} / \mathrm{m} 3$. It is promising to use SVE combination techniques in the SVOCs contaminated soil remediation, through change soil properties or optimize operating parameters, due its good efficient and economical.
\end{abstract}

Keywords- soil vapor extraction; SVOCs; contaminated soil

\section{INTRODUCTION}

Rapid economic growth and lack of focus on environmental protection had brought soil and groundwater contamination problem [1-2]. Pollutants such as heavy metal, volatile organic compounds (VOCs), semi-volatile organic compounds (SVOCs) and chlorinated pesticide are usually toxic and sometimes carcinogenic. SVOCs were a group of popular pollutants that were often detected in brownfields [3] and recalcitrant to natural degradation process with a limited volatility. As a result, the most abundant chemicals found in the contaminated sites were SVOCs [4], which usually accumulates in soil and could become potential threat to public health due to exposure throughout inhalation, ingestion and skin contact [5].

A variety of different remediation technologies, such as chemical oxidation, chemical washing, and thermal desorption, and bioremediation [6], could be optimized for SVOCs contaminated soil treatment. Although chemical or thermal treatments could become effective for SVOCs contaminated soils once the optimal treatment conditions were met, the high chemicals expense and fuel cost in both treatments limited the application of these approaches. On the other hand, bioremediation has become increasingly popular in recent years, as a result of recent advances in environmental biology and bioengineering technology [7]. However, few bioremediation examples were found in domestic engineering practice since SVOCs were usually artificial chemicals and could not be easily degraded with indigenous microorganisms. In addition, bioremediation usually requires prolonged treatment period and sometimes need further analysis and monitoring on microbial community profiles.
An SVE system consists of one or more extraction wells screened in the unsaturated zone, blowers or vacuum pumps with optional air injection or pressure venting wells, a low permeability cap at the ground surface and other supporting components such as air/water separator and offgas treatment system. Airflow is induced in the unsaturated zone by creating a pressure gradient through the injection or withdrawal of air from wells or trenches in the subsurface, enhancing evaporation of contaminants dissolved in pore water and desorption of pollutants from the surfaces of soil particles [8]. Since SVE system is often reusable and does not needs to consume chemicals except offgas treatment, SVE is considered be one of the most effective and cost-efficient methods of removing semi-volatile organic compounds from unsaturated zone [9]. In addition, SVE could also be combined with other remediation technologies such as air sparging [10], bioremediation [11], etc.

The objective of this study was to investigate the potential of SVE treatment for a SVOCs contaminated site by applying a pilot-scale system to testify the feasibility of SVE treatment for ortho-toluidine, one of the primary SVOCs contaminants found in the experiment site. In addition, supplemental treatments such as chemical oxidation and thermal treatment were also selected to apply in practice together with SVE system with different combo treatment design. Optimal operation parameters of the selected SVE system and average treatment cost were also discussed.

\section{MATERIALS AND METHODS}

\section{A. Site Description}

The brownfield site was located in proximity of Ningbo city, with a total area of 4.7 hectares. The site was used for pesticide, herbicide and intermediates manufacturing from 1970 to 2004. Preliminary environmental site assessment provided that the ortho-toluidine is one of the main pollutants in this site and distributed in the region of ortho-toluidine workshop. The concentrations of ortho-toluidine in the contaminated soil were in the range of 0.66 to $191 \mathrm{mg} / \mathrm{kg}$.

\section{B. SVE System}

A pilot-scale SVE system (overall size is about $1400 \times 600 \times 600 \mathrm{~mm}$ ) was designed and constructed by a thirdparty company with SVE system building experience. The system includes gas extraction line, vacuum fan (mediumpressure blower, $2 \mathrm{kw}$ ), moisture separator, tail-gas treatment 
unit and instrumentations. Under the action of air pressure, volatile pollutants were mobilized into the pipeline with steam. Water and gas were separated in the moisture separator, and volatile pollutants were adsorbed by activated carbon at tail-gas treatment unit. Two piezometers and a flowmeter were installed to measure air inlet pressure, air outlet pressure and pipe-flow. Performance of this extraction system was measurement with a preoperational test.

\section{Pilot-scale Experiment}

Onsite pilot experiment was operated in a work shed. A total of 10 cubic meters of contaminated soil was excavated by a power shovel and sorted evenly into 5 piles on ground. Four treatment piles and a control pile were set up as shown in Table 1. Two filter pipes were buried in each SVE treatment pile before the start of the experiment. Four 3kw heating pipes were also pre-buried when the soil needs heating. Oxidant was wellmixed with contaminated soil and shield with canvas for 2 days in chemical oxidation treatments. Soil samples from 5 piles were collected before the treatment and five days after. All samples were analyzed by a third party agency under the EPA method 8270D to examine the concentrations of ortho-toluidine in each sample. All of these were carried out in triplicate.

TABLE I. TEST MATRIX FOR TREATMENTS.

\begin{tabular}{|c|c|c|}
\hline Pile & Treatment & Operation \\
\hline $\mathrm{A}$ & SVE & $\begin{array}{l}\text { Intermittent operation with } 12 \mathrm{~h} \\
\text { extraction and } 12 \mathrm{~h} \text { halt; total elapsed } \\
\text { time is } 3 \text { days }\end{array}$ \\
\hline B & Heating SVE ${ }^{\mathrm{a}}$ & $\begin{array}{l}\text { Intermittent heating with } 2 \mathrm{~h} \text { heating and } \\
2 \mathrm{~h} \text { stop when SVE operating; maximum } \\
\text { heating temperature is } 60^{\circ} \mathrm{C}\end{array}$ \\
\hline $\mathrm{C}$ & Chemical oxidation & $1 \%$ persulfate oxidant added \\
\hline $\mathrm{D}$ & $\begin{array}{l}\text { Chemical oxidation + } \\
\text { SVE }^{\mathrm{a}}\end{array}$ & $\begin{array}{l}\text { SVE system started working after } \\
\text { oxidation treatment completed }\end{array}$ \\
\hline CK & -- & Without any treatment \\
\hline
\end{tabular}

a. The method of SVE operation in pile B and D was same as pile A.

\section{RESULTS AND DISCUSSIONS}

\section{A. Extraction Performance Analysis}

A preoperational test was executed without contaminated soil. Through adjusting inlet valves, air inlet and outlet pressures were changed with pipe-flow. Performance curves of this extraction system were recorded as shown in the Figure 1.

Figure 1 showed a significant inverse correlation between inlet negative pressure and pipe-flow. The inlet negative pressure provides an indication of extraction system resistance determined by soil porosity and batch treatment capacity. Good porosity and permeability soil produce less resistance and could achieve higher extraction flow. Poor permeability soil needs it to reduce bath treatment capacity to get less negative pressure and adequate flow.

\section{B. Treatment Effect}

Removal rates of 5 piles were shown in Figure 2. Pile A was treated with SVE system only and the results showed that the overtime removal rate of pile A is about $17 \%$. Although it is easy to conclude that using SVE treatment in this study did have limited effect on ortho-toluidine removal, we also found that the high soil moisture and compact soil texture also prevented airflow in soil particles and undermined the pressure radius. After treatment, about $80 \%$ of ortho-toluidine in Pile C was oxidized, however we did find that the oxidant could only partially degrade ortho-toluidine into a group of its derivatives, rather than complete breakdown into carbon dioxide and nitrate. These derivatives such as nitrobenzene, benzoquinone were also SVOCs and would continue to pose a threat to environmental public health. Pile B and D used combination technologies of chemical oxidation with SVE and heating SVE. Pile B obtained a better effect than pile A with $79 \%$ orthotoluidine degradation. It manifested that heating treatment could effectively improve pollutant desorption from soil particles while increasing temperature could also enhance the contaminants evaporation from soil moisture. Pile D data was the best treatment results among all 4 different treatments, with about $89 \%$ of ortho-toluidine being removed from soil, the results also indicated that using oxidation to breakdown orthotoluidine and venting the pollutant and its derivatives by SVE system could become effective combo solutions since chemicals oxidation reaction could be greatly enhanced by venting the volatile derivatives using SVE system and allowing more contaminants to be oxidized in a pseudo-steady state. Compare results of pile $\mathrm{C}$ and $\mathrm{D}$, SVE can further increase removal rate about $10 \%$, which demonstrated combination of chemical oxidation and SVE is feasible. Power and chemical costs also calculated in this study and converted to costremoval ratio. With the raising of the removal rate, costremoval ratio is also increased in general. However, pile D has higher removal rate and lower cost-removal ratio. It indicated that SVE combined with chemical oxidation, costs 216 RMB for a cubic meter of soil treatment, is an efficient and economical technology.

Further study on key factors that affect remediation efficiency is highly recommended, which includes operating parameters (temperature, pressure and airflow) [12], pollutant properties (solubility and saturated vapor pressure) [13] and soil properties (porosity, moisture content and organic content) [14]. This study is a beneficial attempt to combine multiple treatment techniques and SVE. In future, it is also high possible to get a better remediation result by adjusting the physical and chemical properties of soil particles and optimizing system buildup and operating parameters.

\section{CONCLUSIONS}

SVE combined with other combo techniques to dispose SVOCs contaminated soil were researched in this study. The results of pilot-scale experiments were indicated that combination technology of chemical oxidation with SVE gets a best remediation effect of $89 \%$ removal and costs $216 \mathrm{RMB} / \mathrm{m} 3$. Through change soil properties or optimize operating parameters, SVE combination techniques have great potential and could become a promising approach in domestic remediation market.

\section{ACKNOWLEDGMENT}

This work was supported by Zhejiang Science and Technology Research Grant (2013F10069, 2014C33051) and 
Zhejiang Environmental Protection Research Grant (2014A008). We would also like to thank Prof. Shen for his generous support during the experiment.

\section{REFERENCES}

[1] J. Zhang, J. Dai, H. Chen, X. Du, W. Wang, R. Wang, Petroleum contamination in groundwater/air and its effects on farmland soil in the outskirt of an industrial city in China, J. Geochemical Explor. 118 (2012) 19-29.

[2] H. Chen, Y. Teng, S. Lu, Y. Wang, J. Wang, Science of the Total Environment Contamination features and health risk of soil heavy metals in China, Sci. Total Environ. 512-513 (2015) 143-153.

[3] Q.Y. Cai, C.H. Mo, Q.T. Wu, A. Katsoyiannis, Q.Y. Zeng, The status of soil contamination by semivolatile organic chemicals (SVOCs) in China: A review, Sci. Total Environ. 389 (2008) 209-224.

[4] N. Zhu, K.-W. Schramm, T. Wang, B. Henkelmann, J. Fu, Y. Gao, et al., Lichen, moss and soil in resolving the occurrence of semi-volatile organic compounds on the southeastern Tibetan Plateau, China, Sci. Total Environ. 518-519 (2015) 328-336.

[5] G. Li, H. Sun, Z. Zhang, T. An, J. Hu, Distribution profile, health risk and elimination of model atmospheric SVOCs associated with a typical municipal garbage compressing station in Guangzhou, South China, Atmos. Environ. 76 (2013) 173-180.
[6] F.I. Khan, T. Husain, R. Hejazi, An overview and analysis of site remediation technologies, J. Environ. Manage. 71 (2004) 95-122.

[7] M. Megharaj, B. Ramakrishnan, K. Venkateswarlu, N. Sethunathan, R. Naidu, Bioremediation approaches for organic pollutants: A critical perspective, Environ. Int. 37 (2011) 1362-1375.

[8] V.T. Nguyen, L. Zhao, R.G. Zytner, Three-dimensional numerical model for soil vapor extraction, J. Contam. Hydrol. 147 (2013) 82-95.

[9] J.F. Campagnolo, A. Akgerman, Modeling of soil vapor extraction (SVE) systems - Part I, Waste Manag. 15 (1995) 379-389.

[10] W. Fan, Y.S. Yang, Y. Lu, X.Q. Du, G.X. Zhang, Hydrogeo-chemical impacts of air sparging remediation on a semi-confined aquifer: Evidences from field monitoring and modeling, Chemosphere. 90 (2013) 1419-1426.

[11] A.A. Soares, J.T. Albergaria, V.F. Domingues, M.D.C.M. Alvim-Ferraz, C. Delerue-Matos, Remediation of soils combining soil vapor extraction and bioremediation: Benzene, Chemosphere. 80 (2010) 823-828.

[12] C.Y. Qin, Y.S. Zhao, W. Zheng, Y.S. Li, Study on influencing factors on removal of chlorobenzene from unsaturated zone by soil vapor extraction, J. Hazard. Mater. 176 (2010) 294-299.

[13] [13] A. a. Jennings, A vapor extraction teaching module based on AIRFLOW/SVE, Environ. Model. Softw. 12 (1997) 335-353.

[14] [14] U. Frank, N. Barkley, Remediation of low permeability subsurface formations by fracturing enhancement of soil vapor extraction, J. Hazard. Mater. 40 (1995) 191-201.

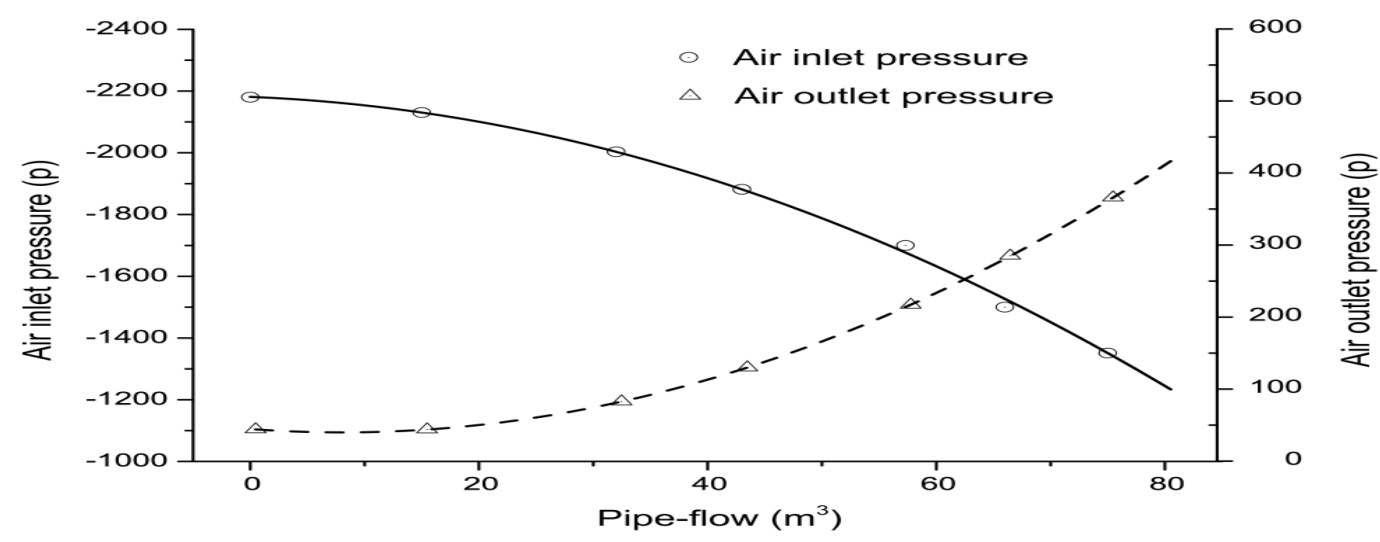

FIGURE I. PERFORMANCE CURVES OF SVE SYSTEM.

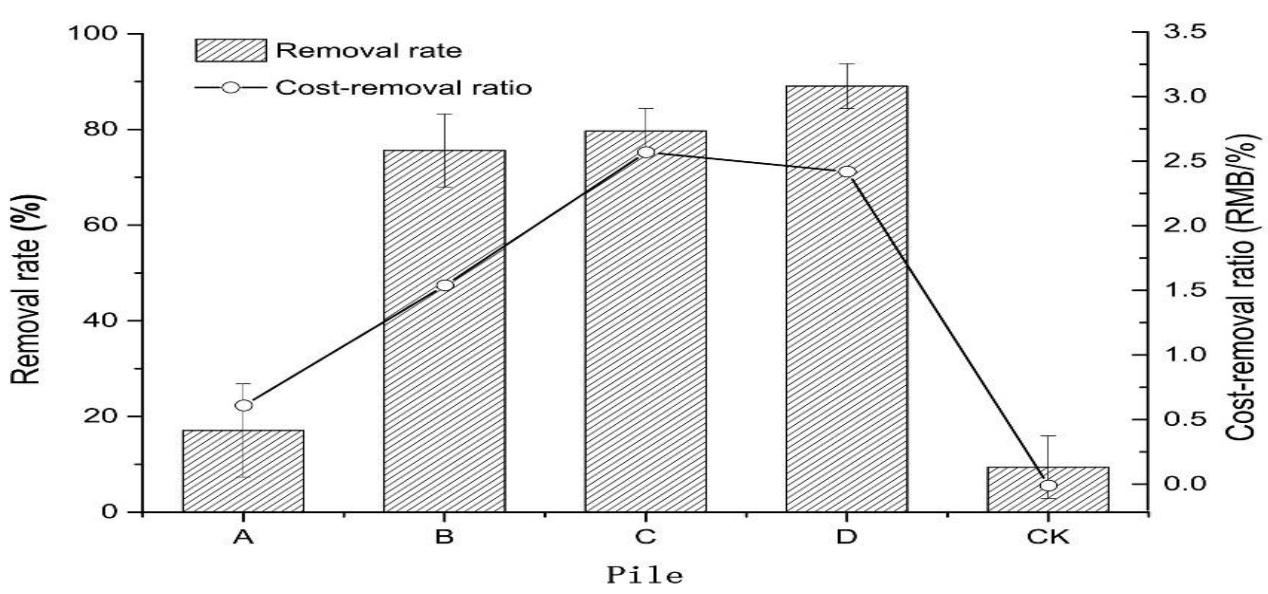

FIGURE II. ORTHO-TOLUIDINE REMOVAL RATE AND COST-REMOVAL RATIO. 